\title{
Associations of Pulmonary Function with Dementia and Depression in an Older Korean Population
}

\author{
Suelin Yoon, Jae-Min Kim $\bowtie$, Hee-Ju Kang, Kyung-Yeol Bae, \\ Sung-Wan Kim, Il-Seon Shin, and Jin-Sang Yoon \\ Department of Psychiatry, Chonnam National University Medical School, Gwangju, Republic of Korea
}

\begin{abstract}
Objective Previous studies reported an association between pulmonary function and cognitive function. However, not much has been investigated in this regard concerning dementia in a community population, taking depression into account. We aimed to examine the associations of pulmonary function with dementia and depression in a community-dwelling elderly population.

Methods A total of 1,038 participants were evaluated for dementia and depression using the Korean version of the Geriatric Mental State Schedule B3 (GMS B3-K), the Community Screening Interview for Dementia-Korean version (CSID-K) and a modified 10-item Word List Learning from the Consortium to Establish a Registry of Alzheimer's Disease (CERAD). Pulmonary function was measured as forced expiratory volume in $1 \mathrm{~s}\left(\mathrm{FEV}_{1}\right)$ from a forced expiratory maneuver.

Results Prevalence rates of dementia and depression were $11.0 \%$ and $10.4 \%$, respectively. Individuals who were diagnosed with dementia manifested a lower mean $\mathrm{FEV}_{1}$, as compared to those without dementia after adjusting for potential confounders, including disability and depression $[\mathrm{OR}=1.34(1.05-1.72)]$. Following gender-stratified analysis, the association was only statistically significant in women $[\mathrm{OR}=1.40(1.04-1.89)]$. The association between depression and mean $\mathrm{FEV}_{1}$ was less significant compared to dementia $[\mathrm{OR}=1.32(1.10-1.58)]$. However, the association was no longer significant after adjusting for age and years of education. No association was significant in the gender-stratified analysis.

Conclusion Decreased pulmonary function was associated with dementia status only in an older female Korean population. Pulmonary function and depression were not significantly associated in either gender.

Psychiatry Investig 2015;12(4):443-450
\end{abstract}

Key Words Pulmonary function, Forced expiratory volume, Dementia, Depression, Disability.

\section{INTRODUCTION}

In the course of aging, pulmonary function declines with associated physiological changes. ${ }^{1}$ Poorer pulmonary function predicts all-cause mortality. ${ }^{2}$ Pulmonary disorder is not only related to physical conditions but is also associated with higher psychiatric morbidity, which decreases quality of life in the elderly. ${ }^{3}$ The psychiatric field has examined pulmonary disorder in relation to several psychiatric disorders, such as cognitive impairment, dementia, and depression.

Cross-sectional studies showed that various pulmonary

Received: November 3, 2014 Revised: January 27, 2015

Accepted: February 11, 2015 Available online: September 30, 2015

$\triangle$ Correspondence: Jae-Min Kim, MD, PhD

Department of Psychiatry, Chonnam National University Medical School, 160 Baekseo-ro, Dong-gu, Gwangju 61469, Republic of Korea

Tel: +82-62-220-6143, Fax: +82-62-225-2351, E-mail: jmkim@chonnam.ac.kr

(a) This is an Open Access article distributed under the terms of the Creative Commons Attribution Non-Commercial License (http://creativecommons.org/licenses/bync/3.0) which permits unrestricted non-commercial use, distribution, and reproduction in any medium, provided the original work is properly cited. measures are associated with cognitive function. ${ }^{4-10}$ Pulmonary function is also correlated with structural brain changes. Sachdev et al. ${ }^{7}$ reported that forced expiratory volume in 1 $s\left(\mathrm{FEV}_{1}\right)$ and forced vital capacity (FVC) could be significant predictors of ventricle-to-brain ratio, an indicator of brain atrophy. In an effort to examine the causative relationship of the association between pulmonary measures and cognitive function, longitudinal studies were also conducted. In those studies, baseline pulmonary function predicted cognitive function later in life. ${ }^{11-13}$ Results from observational studies focused on specific cognitive disorders suggest that pulmonary function predicts mild cognitive impairment or dementia in late life. ${ }^{14-16}$

With respect to depression, the bidirectional relationship between depression and physical health is well known. Poor physical health is a risk factor for depression ${ }^{17-19}$ and depression influences the outcomes of underlying medical illness and mortality. ${ }^{20-22}$ Of various medical illnesses, depressive symptoms are often recognized in patients with pulmonary 
disorders. Not only is depression prevalent in chronic obstructive pulmonary disease (COPD) but it is also related to disease outcome, hospital stay, and physical and social functioning. ${ }^{23}$ In an effort to understand this association, both psychological and physiological models were suggested in COPD patients, ${ }^{24}$ inferring that the relationship between pulmonary function and depression is complex.

Previous studies on the associations of pulmonary function with dementia and depression have typically been carried out in patients with specific pulmonary disorders, particularly COPD. ${ }^{3,25-27}$ There have been few studies conducted in a community population, ${ }^{4,12,15,16}$ which would be more generalizable in elderly populations as a whole. Furthermore, the direct association between depression and pulmonary function has rarely been tested. ${ }^{25,28}$

In our study, we examined the associations of pulmonary function, as measured by $\mathrm{FEV}_{1}$, with dementia and depression in a Korean community-dwelling elderly population.

\section{METHODS}

\section{Sampling and data collection}

Study data were drawn from a larger prospective community survey (from 2001 to 2006) of late life psychiatric morbidity in collaboration with the 10/66 International Dementia Research Program in Developing Countries. ${ }^{29}$ All community residents aged 65 or older within a defined geographic area of Gwangju, South Korea, were systematically identified from national registration lists and were approached to participate. The data for this study were collected in 2006. A letter explaining the study was sent to all potential participants identified before the survey. Home-based interviews were administered to all participants by research nurses who were trained and supervised by the project psychiatrist. The study was approved by the Chonnam National University Hospital Institutional Review Board, and all participants or their family members provided formal written informed consent.

\section{Ascertainment of dementia and depression}

The participants completed the Korean version of the Geriatric Mental State Schedule B3 (GMS B3-K), ${ }^{30}$ the Community Screening Interview for Dementia-Korean version (CSIDK), ${ }^{31}$ and a modified 10-item Word List Learning from the Consortium to Establish a Registry of Alzheimer's Disease (CERAD). The GMS B3 is a fully structured diagnostic interview in wide international use with an accompanying Automated Geriatric Examination for Computer Assisted Taxonomy (AGECAT) algorithm that provides likelihoods of individual diagnoses for mental disorders, including organicity and depression. The GMS B3 was translated into Korean according to a formal standardization process. ${ }^{32}$ A dementia diagnosis was made using a 10/66 dementia diagnostic algorithm using the results derived from the three above measures. ${ }^{29}$ Depression was diagnosed using the GMS B3, in which a 'stage one' (non-hierarchical) confidence level of three or above in the AGECAT algorithm was used. The instrument and algorithm were designed to define current depression present at a level of severity warranting clinical intervention, and focuses on the one-month time period preceding the interview. Here, 'case-level depression' encompasses both moderate and severe symptomatology, and therefore represents a broader syndrome than major depression as defined by the Diagnostic and Statistical Manual of Mental Disorders, Fourth Edition (DSM-IV).

\section{Pulmonary function}

Pulmonary function was measured as forced expiratory volume in $1 \mathrm{~s}\left(\mathrm{FEV}_{1}\right)$ from a forced expiratory maneuver. For the assessment, participants were instructed to perform a spirometry test using a peak flow meter. The test was performed on two occasions, resulting in a mean $\mathrm{FEV}_{1}$. In the area of internal medicine, the spirometry test is a basic and standardized method for evaluating pulmonary function and detecting various lung diseases. ${ }^{33}$ Of the various measures of the spirometry test, the $\mathrm{FEV}_{1}$ is by far the most frequently used and the sensitive index, which was applied for not only those with lung diseases but also for psychiatric patients such as dementia or depression. ${ }^{4,7,8,13,17}$

\section{Covariates}

Covariates potentially associated with the relationships between dementia/depression and pulmonary function were evaluated. ${ }^{34}$ Data on socio-demographic variables, such as age, gender, marital status, education, religion, past and current occupation and accommodation status were collected from participants and family members. For the lung disease covariates, information on asthma and persistent coughing diagnoses and treatment histories, and a smoking history were obtained by self-report and corroborated with a family member when possible. Disability was assessed using the Korean version of the World Health Organization Disability Assessment Schedule (WHO-DAS II). ${ }^{35}$

\section{Statistical analyses}

Data analysis was performed using Statistical Package for the Social Sciences (SPSS 21; SPSS Inc., Chicago, IL, USA). Chi-squared and t-tests were used for the descriptive analysis of dementia and depression status. The prevalence rates of dementia and depression with $95 \%$ confidence intervals (95\% CIs) are presented by mean $\mathrm{FEV}_{1}$ quartile. In univariate 
Table 1. Characteristics of study participants by dementia and depression status

\begin{tabular}{|c|c|c|c|c|c|c|}
\hline & \multicolumn{3}{|c|}{ Dementia analysis } & \multicolumn{3}{|c|}{ Depression analysis } \\
\hline & $\begin{array}{c}\text { No dementia } \\
\mathrm{N}=924\end{array}$ & $\begin{array}{c}\text { Dementia } \\
\mathrm{N}=114\end{array}$ & $\mathrm{p}$-value & $\begin{array}{c}\text { No depression } \\
\quad \mathrm{N}=927\end{array}$ & $\begin{array}{c}\text { Depression } \\
\mathrm{N}=108\end{array}$ & p-value \\
\hline Age, years (SD) & $72.8(6.5)$ & $78.1(7.6)$ & $<0.001$ & $73.1(6.7)$ & $75.6(7.2)$ & $<0.001$ \\
\hline Gender (female), N (\%) & $579(62.7)$ & $97(85.1)$ & $<0.001$ & $588(63.4)$ & $86(79.6)$ & $<0.01$ \\
\hline Education years (SD) & $5.0(4.4)$ & $1.4(3.0)$ & $<0.001$ & $4.8(4.5)$ & $2.2(3.2)$ & $<0.001$ \\
\hline Married, N (\%) & $520(56.3)$ & $24(21.1)$ & $<0.001$ & $512(55.2)$ & $31(28.7)$ & $<0.001$ \\
\hline Religion (have), N (\%) & $598(35.3)$ & $81(28.9)$ & 0.210 & $601(64.8)$ & $108(10.4)$ & 0.200 \\
\hline Accommodation (rented), N (\%) & $223(24.1)$ & $53(46.5)$ & $<0.001$ & $233(25.1)$ & $41(38.0)$ & $<0.01$ \\
\hline Past occupation (manual), N (\%) & $765(82.8)$ & $108(94.7)$ & $<0.001$ & $770(83.1)$ & $101(93.5)$ & $<0.01$ \\
\hline Current occupation (No), N (\%) & $846(91.6)$ & $112(98.2)$ & $<0.01$ & $853(92.0)$ & $102(94.4)$ & 0.450 \\
\hline Asthma, N (\%) & $126(13.7)$ & $22(19.3)$ & 0.118 & $124(13.4)$ & $24(22.2)$ & $<0.05$ \\
\hline Persistent cough, N (\%) & $93(10.1)$ & $22(19.3)$ & $<0.01$ & $93(9.8)$ & $23(21.3)$ & $<0.01$ \\
\hline Current smoking, N (\%) & $189(20.5)$ & $19(16.7)$ & 0.387 & $194(20.9)$ & $12(11.1)$ & $<0.05$ \\
\hline WHODAS score (SD) & $35.8(21.8)$ & $49.0(19.9)$ & $<0.001$ & $35.6(21.6)$ & $51.7(19.8)$ & $<0.001$ \\
\hline
\end{tabular}

SD: standard deviation, WHODAS: The World Health Organization Disability Assessment Schedule

analysis, associations among mean $\mathrm{FEV}_{1}$ and participant characteristics were assessed using logistic regression analysis. For multivariate analysis, logistic regression models were introduced by entering mean $\mathrm{FEV}_{1}$ quartile as a numerical variable to reach statistical significance. In multivariate logistic regression models, associations between mean $\mathrm{FEV}_{1}$ and dementia/depression status were evaluated after stratifying for sex, considering anatomical differences in lung volume. For each analysis of dementia and depression status, variables that were significantly different in the univariate analysis were subsequently entered. Additionally, variables such as religion, current occupation, asthma, and current smoking status were entered after controlling for possible confounding effects.

\section{RESULTS}

\section{Recruitment}

Of the 2,201 community residents aged 65 or older identified, 1,038 (47\%) completed the assessment and participated in the study. There was no significant difference between participants and non-participants regarding age or gender (all $\mathrm{p}<0.05)$. Among the 1,038 participants who completed the assessment, 676 (65.1\%) were female. The mean age was 73.4 (standard deviation, $\mathrm{SD}=6.84) ; 114(11.0 \%)$ were diagnosed with dementia and 108 (10.4\%) had case-level depression.

\section{Association of participant characteristics with dementia and depression}

Participant characteristics by dementia and depression status are presented in Table 1. For dementia, characteristics such as older age, being female, lower education, unmarried status, rented accommodations, past manual occupation and greater disability were associated with disorder status (all $\mathrm{p}<0.001)$. Current occupation $(\mathrm{p}=0.008)$ and persistent coughing $(p=0.006)$ were also associated, but with lesser statistical significance. There were no differences in region, asthma or current smoking status between the dementia and non-dementia groups.

Depression status was associated with older age $(\mathrm{p}<0.001)$, being female $(p<0.01)$, less education $(p<0.001)$, unmarried status ( $\mathrm{p}<0.001)$, rented accommodations $(\mathrm{p}<0.01)$, past manual occupation $(\mathrm{p}<0.01)$, asthma $(\mathrm{p}<0.05)$, persistent coughing $(\mathrm{p}<0.01)$, not currently smoking $(\mathrm{p}<0.05)$, and greater disability $(\mathrm{p}<0.001)$. No significant differences were found regarding religion or current occupation status between the depressed and non-depressed groups.

Prevalence of dementia and depression by mean $\mathrm{FEV}_{1}$

Figure 1 shows prevalence rates of dementia and depression by mean $\mathrm{FEV}_{1}$ quartile. For dementia, prevalence rates were $4.8 \%, 4.7 \%, 10.7 \%, 22.9 \%\left(\chi^{2}=59.4, \mathrm{p}<0.001\right)$ for each mean $\mathrm{FEV}_{1}$ quartile from lowest to highest. Participants with lower pulmonary function were more likely to be diagnosed with dementia. Prevalence rates of depression for mean $\mathrm{FEV}_{1}$ quartile were $6.8 \%, 9.1 \%, 11.1 \%, 14.4 \%$, respectively $\left(\chi^{2}=8.9\right.$, $\mathrm{p}=0.031$ ). The trend of increased prevalence in lower pulmonary function was similar to that of dementia, but the significance was less.

\section{Associations between $\mathrm{FEV}_{1}$ and participant characteristics}

Associations among participant characteristics and mean 

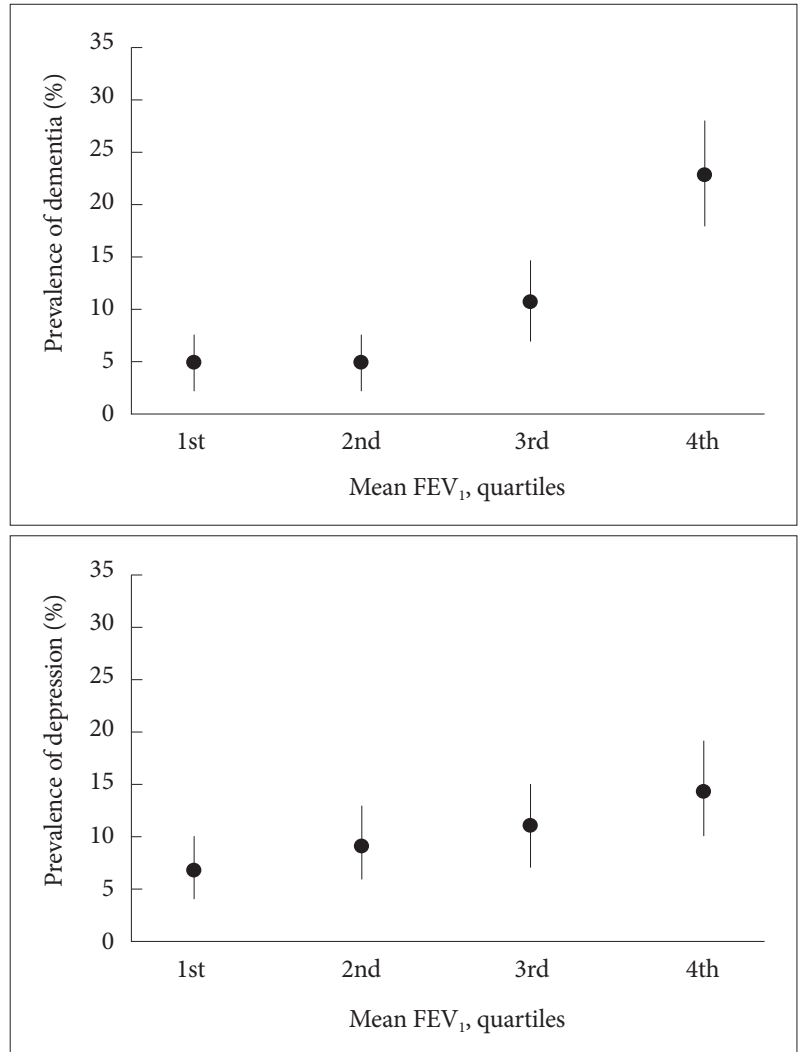

Figure 1. Prevalence rates of dementia and depression by forced expiratory volume in one second $\left(\mathrm{FEV}_{1}\right)$ quartiles.

$\mathrm{FEV}_{1}$ are shown in Table 2. Those aged 75 or older had a lower mean $\mathrm{FEV}_{1}$ compared to those aged 65 to $74(\mathrm{p}<0.001)$. Subjects who were female, uneducated, unmarried, practiced religion, and living in a rented accommodation had lower mean $\mathrm{FEV}_{1}$. With regard to occupational status, those who engaged in a past manual occupation and were currently without an occupation had a lower mean $\mathrm{FEV}_{1}$. Participants with asthma, persistent coughing, and non-smokers were more likely to have a lower mean $\mathrm{FEV}_{1}$. Greater disability, as defined as a WHODAS score $>1$, was associated with a lower mean $\mathrm{FEV}_{1}$.

\section{Multivariate associations of dementia and depression with $\mathrm{FEV}_{1}$}

Total and gender stratified multivariate analyses are summarized in Table 3. For dementia, the unadjusted odds ratio (OR) for mean $\mathrm{FEV}_{1}$ was 2.02 ( $\mathrm{OR}=2.02$; 95\% $\left.\mathrm{CI}=1.64-2.48\right)$. The association remained significant but weakened after subsequently entering variables $(\mathrm{OR}=1.34 ; 95 \% \mathrm{CI}=1.05-1.72)$. In a separate analysis, the association was not detected in males after adjusting for age and years of education. On the contrary, we detected a significant association between dementia status and mean $\mathrm{FEV}_{1}$ in the female group, even after adjusting for depression status ( $\mathrm{OR}=1.40$; 95\% $\mathrm{CI}=1.04-1.89)$.
Table 2. Associations with forced expiratory volume in one second $\left(\mathrm{FEV}_{1}\right)$ and characteristics

\begin{tabular}{|c|c|c|c|}
\hline Characteristic & Number (\%) & $\mathrm{FEV}_{1}(\mathrm{SD}), \mathrm{mL}$ & p-value \\
\hline Age, years* & & & $<0.001$ \\
\hline $65-74$ & $626(60.3)$ & $242.4(91.0)$ & \\
\hline $75+$ & $411(39.6)$ & $194.2(88.1)$ & \\
\hline Gender & & & $<0.001$ \\
\hline Male & $362(34.9)$ & $277.2(108.4)$ & \\
\hline Female & $676(65.1)$ & $194.3(67.6)$ & \\
\hline Education, years* & & & $<0.001$ \\
\hline 0 & $372(35.8)$ & $179.8(72.2)$ & \\
\hline $1+$ & $665(64.1)$ & $247.5(94.4)$ & \\
\hline Marital status & & & $<0.001$ \\
\hline Married & $544(52.4)$ & $249.0(97.5)$ & \\
\hline Unmarried & $494(47.6)$ & $194.9(78.3)$ & \\
\hline Religion & & & $<0.01$ \\
\hline Have & $679(65.4)$ & $216.8(90.8)$ & \\
\hline No & $359(34.6)$ & $235.4(95.6)$ & \\
\hline Accommodation & & & $<0.001$ \\
\hline Owned & $762(73.4)$ & $235.1(94.1)$ & \\
\hline Rented & $276(26.6)$ & $190.4(80.8)$ & \\
\hline Past occupation & & & $<0.001$ \\
\hline Non-manual & $165(15.9)$ & $292.5(105.7)$ & \\
\hline Manual & $873(84.1)$ & $210.1(84.1)$ & \\
\hline Current occupation & & & $<0.05$ \\
\hline No & $958(92.3)$ & $221.1(92.3)$ & \\
\hline Have & $80(7.7)$ & $248.6(96.7)$ & \\
\hline Asthma* & & & $<0.001$ \\
\hline No & $889(85.7)$ & $231.5(94.2)$ & \\
\hline Have & $148(14.3)$ & $174.2(65.7)$ & \\
\hline Persistent cough* & & & $<0.001$ \\
\hline No & $922(88.8)$ & $226.8(93.4)$ & \\
\hline Have & $115(11.1)$ & $194.2(84.0)$ & \\
\hline Current smoking & & & $<0.001$ \\
\hline No & $830(80.0)$ & $213.1(86.1)$ & \\
\hline Yes & $208(20.0)$ & $263.5(107.1)$ & \\
\hline WHODAS score & & & $<0.001$ \\
\hline 0 & $145(14.0)$ & $283.1(96.5)$ & \\
\hline $1+$ & $893(86.0)$ & $213.5(88.6)$ & \\
\hline
\end{tabular}

*missing data (age, education, asthma, persistent coughing=1 missing, physical illness=7 missing). WHODAS: The World Health Organization Disability Assessment Schedule

The association between depression and mean $\mathrm{FEV}_{1}$ was less significant, as compared to dementia $(\mathrm{OR}=1.32 ; 95 \% \mathrm{CI}=1.10$ -1.58) (Table 4). The association was not significant after adjusting for age, gender, and years of education. The association was no longer significant following gender stratification. 
Table 3. Models for association between forced expiratory volume in one second $\left(\mathrm{FEV}_{1}\right)$ and dementia status

\begin{tabular}{cccc}
\hline \multirow{2}{*}{ Models } & \multicolumn{3}{c}{ Dementia $\times$ FEV $_{1}$} \\
\cline { 2 - 4 } & All participants & Male & Female \\
\hline Model 1 & $2.02(1.64-2.48)^{\ddagger}$ & $1.63(1.07-2.47)^{*}$ & $1.96(1.52-2.53)^{\ddagger}$ \\
Model 2 & $1.39(1.10-1.75)^{\dagger}$ & $1.29(0.81-2.04)$ & $1.45(1.10-1.91)^{\dagger}$ \\
Model 3 & $1.35(1.06-1.72)^{*}$ & $1.21(0.75-1.97)$ & $1.41(1.06-1.88)^{*}$ \\
Model 4 & $1.34(1.05-1.72)^{*}$ & $1.06(0.62-1.80)$ & $1.42(1.06-1.90)^{*}$ \\
Model 5 & $1.31(1.03-1.68)^{*}$ & $1.04(0.61-1.77)$ & $1.37(1.02-1.84)^{*}$ \\
Model 6 & $1.34(1.05-1.72)^{*}$ & $1.04(0.61-1.80)$ & $1.40(1.04-1.89)^{*}$ \\
\hline
\end{tabular}

Model 1: Unadjusted, Model 2: Model 1+age ( $75<$ or not), gender, education years, Model 3: Model 2+marital status, religion, accommodation, past occupation, current occupation, Model 4: Model 3+asthma, persistent cough, current smoking, Model 5: Model 4+WHODAS score, Model 6: Model 5+depression status. ${ }^{*} \mathrm{p}<0.05$, ${ }^{\dagger} \mathrm{p}<0.01,{ }^{\ddagger} \mathrm{p}<0.001$

Table 4. Models for association between forced expiratory volume in one second $\left(\mathrm{FEV}_{1}\right)$ and depression status

\begin{tabular}{cccc}
\hline \multirow{2}{*}{ Models } & \multicolumn{3}{c}{ Depression $\times$ mean $\mathrm{FEV}_{1}$} \\
\cline { 2 - 4 } & All participants & Male & Female \\
\hline Model 1 & $1.32(1.10-1.58)^{\dagger}$ & $1.33(0.92-1.92)$ & $1.17(0.93-1.47)$ \\
Model 2 & $0.97(0.78-1.21)$ & $1.08(0.72-1.63)$ & $0.94(0.73-1.22)$ \\
Model 3 & $0.95(0.76-1.18)$ & $1.09(0.72-1.64)$ & $0.91(0.70-1.17)$ \\
Model 4 & $0.91(0.72-1.14)$ & $0.92(0.59-1.45)$ & $0.87(0.67-1.14)$ \\
Model 5 & $0.87(0.69-1.10)$ & $0.86(0.54-1.37)$ & $0.83(0.63-1.09)$ \\
Model 6 & $0.84(0.67-1.07)$ & $0.86(0.54-1.37)$ & $0.78(0.59-1.04)$ \\
\hline
\end{tabular}

Model 1: Unadjusted, Model 2: Model 1+age (75< or not), gender, education years, Model 3: Model 2+marital status, religion, accommodation, past occupation, current occupation, Model 4: Model 3+asthma, persistent cough, current smoking, Model 5: Model 4+WHODAS score, Model 6: Model 5+depression status. ${ }^{*} \mathrm{p}<0.05$, ${ }^{\dagger} \mathrm{p}<0.01,{ }^{\ddagger} \mathrm{p}<0.001$

\section{DISCUSSION}

Principal findings of this cross-sectional study in a community-dwelling older Korean population were that poorer pulmonary function, as measured by $\mathrm{FEV}_{1}$, was associated with dementia, independently of covariates, including pulmonary disease and smoking status. This association was only significant in women. However, no significant association was found between $\mathrm{FEV}_{1}$ and depression in either sex.

Several plausible possibilities could explain the significant association between lower $\mathrm{FEV}_{1}$ and dementia. One possibility is that decreased pulmonary function leads to insufficient oxygenation and other biological consequences that affect the brain. The brain is one of the most metabolically active organs, consuming $20 \%$ of bodily energy due to oxygen consumption, ${ }^{36}$ and cerebral oxygenation is fundamental for proper functioning. Decreased brain oxygenation could lead to neuronal damage that could further manifest as cognitive decline. Chronic hypoxia, whether continuous or intermittent, reportedly interfered with myelination in the cerebral cortex and hippocampus in a mouse model. ${ }^{37}$ In severe COPD with hypoxia, increased risk of cognitive decline was reported, suggesting hypoxia-induced neuronal damage. ${ }^{27}$ Hypoperfusion in specific brain areas was detected using single photon emission computed tomography (SPECT) in COPD. More hypoperfusion was detected in demented groups, suggesting a correlation between cognitive decline and pulmonary function. ${ }^{26}$ Second, an inflammation-related mechanism has also been suggested. It was demonstrated that even acute hypoxia could induce lung inflammation. ${ }^{38}$ An Alzheimer's disease study demonstrated the presence of inflammation, providing evidence of various inflammatory markers and their involvement in cognitive deterioration. ${ }^{39}$ In prospective studies, baseline inflammatory markers predict later cognitive performance. ${ }^{40,41}$ Inflammation due to pulmonary insufficiency could directly or indirectly influence developmental processes of dementia by increasing other risk factors for dementia. Third, a brain-derived neurotrophic factor (BDNF) hypothesis of dementia was proposed. Physical activity was examined in association with BDNF expression, which is presumed to promote neuroplasticity. ${ }^{42}$ Elderly individuals with decreased pulmonary function are less likely to be involved in physical activity that could sustain or promote cognitive function, thus increasing dementia risk. Our study indicates that the association between pulmonary function and cognitive function is not explained by functional disability alone, given that the association was significant even after controlling for WHODAS score. However, whether individuals were involved in regular exercise in spite of having a certain functional disability was unknown. Further, it is possible that a higher WHODAS score resulted from different dimensions of disability other than physical activity alone.

Reverse causality might also be possible, in that dementia could affect pulmonary function through certain physiological changes, although this hypothesis is less popular. Subjects with dementia may have limited capability to prevent, detect early and treat pulmonary disorder. Decreased pulmonary function in the dementia group may indicate that their mental health condition hindered them from engaging in sustaining their physical health. Pulmonary problems could be considered to be not only a respiratory but also a systemic condition associated with other physical causes and consequences. In this study, subjects with dementia were more likely to have persistent coughing and more physical illness (data not shown). However, the association was still significant after adjusting for these factors, even after including the number of physical illnesses (data not shown), indicating 
that the effect cannot be explained by a physically-ill state.

Interestingly, the association was only significant in females in our study. In males, the association disappeared after controlling for age and education. Specifically, adjusting for education alone did not change the significance in either sex, but the significance disappeared after taking age into consideration in males. Considering the previously mentioned possible mechanisms, females may have a different sensitivity to hypoxia or other physical changes associated with decreased pulmonary function, as compared to males. de Leeuw and colleagues ${ }^{43}$ reported a higher incidence of subcortical and periventricular white matter lesions in females, as compared to males, related to a higher incidence of dementia among the female population. Increased susceptibility to cerebral hypoxia due to hormonal changes after menopause (decrease in estrogen level) was suggested to be the reason. A lesser protective role of sex hormones in elderly females may provide a clue to understand the sex specific association in the present study. There are also studies reporting anthropometric measures, such as shorter leg length and smaller head circumference, associated with dementia, also only in females, similar to our study. ${ }^{44,45}$ The reason for the sex difference needs to be further elucidated, but the gender specific association is in line with results of the present study. It is also generally acknowledged that females are at a higher risk for dementia.

Regarding depression, we found no association between its incidence and pulmonary function. Although we did not detect a statistically significant association between pulmonary function and depression, most studies support an increased risk of depression in pulmonary disorder. ${ }^{24}$ However, there are reports that failed to find an association between $\mathrm{FEV}_{1}$ and depression status. ${ }^{23,28}$ Unlike dementia, which is more related to biophysiological processes, depression may be more related to psychological and emotional conditions in pulmonary disorders, which could explain our results. Pulmonary function is reportedly a predictor of quality of life in relation to functional impairment and depression. ${ }^{3}$ In this study, quality of life was not measured; taking quality of life into consideration may have revealed a moderating effect. The prevalence of depression in this study was approximately $10 \%$, which is similar to results from other studies using the same depression diagnosis tool. ${ }^{46}$ It is also possible that the pulmonary dysfunction was not severe enough to detect the association in this population, considering that previous studies reporting a correlation between pulmonary function and depression were mostly executed in patients with specific pulmonary disorders.

The strength of this study lies in its large, communitybased population from a well-validated database. Instead of relating pulmonary and cognitive function using various ranges of age groups, a relatively narrow age group was used to reduce individual differences in cognition due to age, specifically focusing on dementia. Since cognitive function, affective conditions and disability are interrelated, ${ }^{34}$ disability was considered and dementia and depression status were entered in the analysis to remove potentially confounding effects. In addition, pulmonary function is known to differ among ethnic groups, resulting in different reference ranges, ${ }^{47}$ in that $\mathrm{FEV}_{1}$ and $\mathrm{FVC}$ values are lower in Asians, as compared to Western populations, suggesting true physiologic differences. ${ }^{48}$ Previous studies concerning dementia and pulmonary function have been mostly conducted in Western countries. To our knowledge, this is the first study to evaluate the relationship in an Asian elderly population.

The major limitation of the present study is related to its cross-sectional design, in that the direction of causality cannot be concluded. Hypoxic state or oxygen saturation level was not monitored in the present study; thus, a direct correlation could not be determined. Further study measuring both peripheral and cerebral oxygenation would be needed to enhance our mechanistic understanding. In addition, although lung disease covariates such as asthma, persistent coughing, and smoking histories were evaluated, but other important variables could have effects on pulmonary function (especially on $\mathrm{FEV}_{1}$ ) were not considered in our study. These factors are not only symptoms (wheezing without cough, chest discomfort without cough, and so on) but also diseases (chronic rhinitis, gastro-esophageal reflux disease, chronic bronchiolitis, emphysema, and so on).

An increase in the elderly population results in various issues, including an increase in both physical and mental disorders, with an accompanying rise in health costs. Dementia is considered to be a devastating disorder of deterioration without a cure. Although dementia treatment trials have been conducted, most studies of the disease are limited to reporting risk factors and preventions. This study presents an association between decreased pulmonary function and dementia without proposing a causal relationship. However, this result may be important, as pulmonary function is a manageable condition. Patients with pulmonary disorders would be considered an at-risk population in which regular evaluation of cognitive function should be recommended and an emphasis placed on pulmonary condition treatment. Also, public education regarding the importance of preserving and sustaining pulmonary health in relation to cognitive decline would be necessary. Future research utilizing a longitudinal design or clinical trials enhancing pulmonary health to improve dementia prevalence and outcomes are needed to clarify this association. 


\section{Acknowledgments}

This work was funded by a grant from the Korean Health Technology R\&D Project, Ministry of Health \& Welfare, Republic of Korea (HI12 C0003).

\section{REFERENCE}

1. Janssens JP, Pache JC, Nicod LP. Physiological changes in respiratory function associated with ageing. Eur Respir J 1999;13:197-205.

2. Hole DJ, Watt GC, Davey-Smith G, Hart CL, Gillis CR, Hawthorne VM. Impaired lung function and mortality risk in men and women: findings from the Renfrew and Paisley prospective population study. BMJ 1996;313:711-715.

3. Peruzza S, Sergi G, Vianello A, Pisent C, Tiozzo F, Manzan A, et al. Chronic obstructive pulmonary disease (COPD) in elderly subjects: impact on functional status and quality of life. Respir Med 2003;97: 612-617.

4. Cook NR, Albert MS, Berkman LF, Blazer D, Taylor JO, Hennekens $\mathrm{CH}$. Interrelationships of peak expiratory flow rate with physical and cognitive function in the elderly: MacArthur Foundation studies of aging. J Gerontol A Biol Sci Med Sci 1995;50:M317-M323.

5. Cerhan JR, Folsom AR, Mortimer JA, Shahar E, Knopman DS, McGovern PG, et al. Correlates of cognitive function in middle-aged adults. Atherosclerosis Risk in Communities (ARIC) Study Investigators. Gerontology 1998;44:95-105.

6. Aleman A, Muller M, de Haan EH, van der Schouw YT. Vascular risk factors and cognitive function in a sample of independently living men. Neurobiol Aging 2005;26:485-490.

7. Sachdev PS, Anstey KJ, Parslow RA, Wen W, Maller J, Kumar R, et al. Pulmonary function, cognitive impairment and brain atrophy in a middle-aged community sample. Dement Geriatr Cogn Disord 2006; 21:300-308.

8. Allaire JC, Tamez E, Whitfield KE. Examining the association between lung functioning and cognitive performance in African American adults. J Aging Health 2007;19:106-122.

9. Min JY, Min KB, Paek D, Sakong J, Cho SI. The association between neurobehavioral performance and lung function. Neurotoxicology 2007;28:441-444.

10. Singh-Manoux A, Dugravot A, Kauffmann F, Elbaz A, Ankri J, Nabi H, et al. Association of lung function with physical, mental and cognitive function in early old age. Age (Dordr) 2011;33:385-392.

11. Chyou PH, White LR, Yano K, Sharp DS, Burchfiel CM, Chen R, et al. Pulmonary function measures as predictors and correlates of cognitive functioning in later life. Am J Epidemiol 1996;143:750-756.

12. Emery CF, Huppert FA, Schein RL. Do pulmonary function and smoking behavior predict cognitive function? Findings from a British sample. Psychol Health 1997;12:265-275.

13. Weuve J, Glymour MM, Hu H, Sparrow D, Spiro A 3rd, Vokonas PS, et al. Forced expiratory volume in 1 second and cognitive aging in men. J Am Geriatr Soc 2011;59:1283-1292.

14. Guo X, Waern M, Sjogren K, Lissner L, Bengtsson C, Björkelund C. Midlife respiratory function and Incidence of Alzheimer's disease: a 29year longitudinal study in women. Neurobiol Aging 2007;28:343-350.

15. Pathan SS, Gottesman RF, Mosley TH, Knopman DS, Sharrett AR, Alonso A. Association of lung function with cognitive decline and dementia: the Atherosclerosis Risk in Communities (ARIC) Study. Eur J Neurol 2011;18:888-898.

16. Vidal JS, Aspelund T, Jonsdottir MK, Jonsson, PV, Harris TB, Lopez OL, et al. Pulmonary function impairment may be an early risk factor for late-life cognitive impairment. J Am Geriatr Soc 2013;61:79-83.

17. Geerlings SW, Beekman AT, Deeg DJ, Van Tilburg W. Physical health and the onset and persistence of depression in older adults: an eightwave prospective community-based study. Psychol Med 2000;30:369380.

18. Schoevers R, Beekman A, Deeg D, Geerlings MI, Jonker C, Van Tilburg W. Risk factors for depression in later life; results of a prospective community based study (AMSTEL). J Affect Disord 2000;59:127-137.

19. Bisschop MI, Kriegsman DM, Deeg DJ, Beekman AT, van Tilburg W. The longitudinal relation between chronic diseases and depression in older persons in the community: the Longitudinal Aging Study Amsterdam. J Clin Epidemiol 2004;57:187-194.

20. Vaccarino V, Kasl SV, Abramson J, Krumholz HM. Depressive symptoms and risk of functional decline and death in patients with heart failure. J Am Coll Cardiol 2001;38:199-205.

21. Schulz R, Drayer RA, Rollman BL. Depression as a risk factor for nonsuicide mortality in the elderly. Biol Psychiatry 2002;52:205-225.

22. Fisch M. Treatment of depression in cancer. J Natl Cancer Inst Monogr 2004;32:105-111.

23. Ng TP, Niti M, Tan WC, Cao Z, Ong KC, Eng P. Depressive symptoms and chronic obstructive pulmonary disease: effect on mortality, hospital readmission, symptom burden, functional status, and quality of life. Arch Intern Med 2007;167:60-67.

24. Mikkelsen RL, Middelboe T, Pisinger C, Stage KB. Anxiety and depression in patients with chronic obstructive pulmonary disease (COPD). A review. Nord J Psychiatry 2004;58:65-70.

25. Van Manen J, Bindels P, Dekker F, IJzermans CJ, Van der Zee JS, Schade E. Risk of depression in patients with chronic obstructive pulmonary disease and its determinants. Thorax 2002;57:412-416.

26. Incalzi RA, Marra C, Giordano A, Calcagni ML, Cappa A, Basso S, et al. Cognitive impairment in chronic obstructive pulmonary disease. J Neurol 2003;250:325-332.

27. Hung WW, Wisnivesky JP, Siu AL, Ross JS. Cognitive decline among patients with chronic obstructive pulmonary disease. Am J Respir Crit Care Med 2009;180:134-137.

28. Di Marco F, Verga M, Reggente M, Maria Casanova F, Santus P, Blasi F, et al. Anxiety and depression in COPD patients: the roles of gender and disease severity. Respir Med 2006;100:1767-1774.

29. Prince M, Acosta D, Chiu H, Scazufca M, Varghese M. Dementia diagnosis in developing countries: a cross-cultural validation study. Lancet 2003;361:909-917.

30. Copeland JR, Dewey ME, Griffiths-Jones HM. A computerized psychiatric diagnostic system and case nomenclature for elderly subjects: GMS and AGECAT. Psychol Med 1986;16:89-99.

31. Kim JM, Kim SW, Shin IS, Zheng TJ, Yoon JS. Development of Korean version of community screening interview for dementia (CSID-K). J Korean Neuropsychiatr Assoc 2004;43:445-451.

32. Kim JM, Stewart R, Prince M, Shin IS, Yoon JS. Diagnosing dementia in a developing nation: an evaluation of the GMS-AGECAT algorithm in an older Korean population. Int J Geriatr Psychiatry 2003;18:331-336.

33. Pierce R. "Spirometry: An essential clinical measurement". Aust Fam Physician 2005;34:535-539.

34. McCullagh CD, Craig D, McIlroy SP, Passmore AP. Risk factors for dementia. Adv Psych Treatment 2001;7:24-31.

35. Kim JM, Stewart R, Glozier N, Prince M, Kim SW, Yang SJ, et al. Physical health, depression and cognitive function as correlates of disability in an older Korean population. Int J Geriatr Psychiatry 2005;20:160-167.

36. Clarke DD, Sokoloff L. Regulation of Cerebral Metabolic Rate. In: Siegel GJ, Agranoff BW, Albers RW, Fisher SK, Uhler MD, Editors. Basic Neurochemistry: Molecular, Cellular and Medical Aspects. 6th Edition. Philadelphia: Lippincott-Raven; 1999.

37. Kanaan A, Farahani R, Douglas RM, Lamanna JC, Haddad GG. Effect of chronic continuous or intermittent hypoxia and reoxygenation on cerebral capillary density and myelination. Am J Physiol Regul Integr Comp Physiol 2006;290:R1105-R1114.

38. Madjdpour C, Jewell UR, Kneller S, Ziegler U, Schwendener R, Booy $\mathrm{C}$, et al. Decreased alveolar oxygen induces lung inflammation. Am J Physiol Lung Cell Mol Physiol 2003;284:L360-L367.

39. Akiyama H, Barger S, Barnum S, Bradt B, Bauer J, Cole GM, et al. Inflammation and Alzheimer's disease. Neurobiol Aging 2000;21:383-421.

40. Teunissen CE, van Boxtel MP, Bosma H, Bosmans E, Delanghe J, De Bruijn C, et al. Inflammation markers in relation to cognition in a 
healthy aging population. J Neuroimmunol 2003;134:142-150.

41. Dik MG, Jonker C, Hack CE, Smit JH, Comijs HC, Eikelenboom P. Serum inflammatory proteins and cognitive decline in older persons. Neurology 2005;64:1371-1377.

42. Gómez-Pinilla F, Ying Z, Roy RR, Molteni R, Edgerton VR. Voluntary exercise induces a BDNF-mediated mechanism that promotes neuroplasticity. J Neurophysiol 2002;88:2187-2195.

43. de Leeuw FE, de Groot JC, Achten E, Oudkerk M, Ramos LMP, Heijboer R, et al. Prevalence of cerebral white matter lesions in elderly people: a population based magnetic resonance imaging study. The Rotterdam Scan Study. J Neurol Neurosurg Psychiatry 2001;70:9-14.

44. Kim J, Stewart R, Shin I, Yoon JS. Limb length and dementia in an older Korean population. J Neurol Neurosurg Psychiatry 2003;74:427-432.
45. Kim JM, Stewart R, Shin IS, Kim SW, Yang SJ, Yoon JS. Associations between head circumference, leg length and dementia in a Korean population. Int J Geriatr Psychiatry 2008;23:41-48.

46. Beekman AT, Copeland JR, Prince MJ. Review of community prevalence of depression in later life. Br J Psychiatry 1999;174:307-311.

47. Quanjer PH, Stanojevic S, Cole TJ, Baur X, Hall GL, Culver BH, et al. Multi-ethnic reference values for spirometry for the 3-95-yr age range: the global lung function 2012 equations. Eur Respir J 2012;40:13241343.

48. Korotzer B, Ong S, Hansen JE. Ethnic differences in pulmonary function in healthy nonsmoking Asian-Americans and European-Americans. Am J Respir Crit Care Med 2000;161:1101-1108. 